\title{
WREN NESTS IN SKULL
}

YVONNE NELSON, Kyle, SK

We have had wrens in our yard for about 8 years. Every morning the chorus wakes us up, starting with the robins and then the wrens. My husband will get up, growl out the window for the birds to shut up and close the window. Then the wren, disturbed by the noise would fly to the kitchen window and continue to sing and sing and sing. Every time he goes outside, the wren seems to come and see what we are up to. I think it is trying to chase off a threat (being us) but we like to think it is coming to see us.

Because the wren song particularly annoys him, everywhere we camp or visit, a wren seems to be nesting nearby and likes to sing in the morning. One Christmas, we received a clock from my sister that could wake us up with a recording of birdsong. Right in the middle of the loop was the wren. We didn't use that setting much.

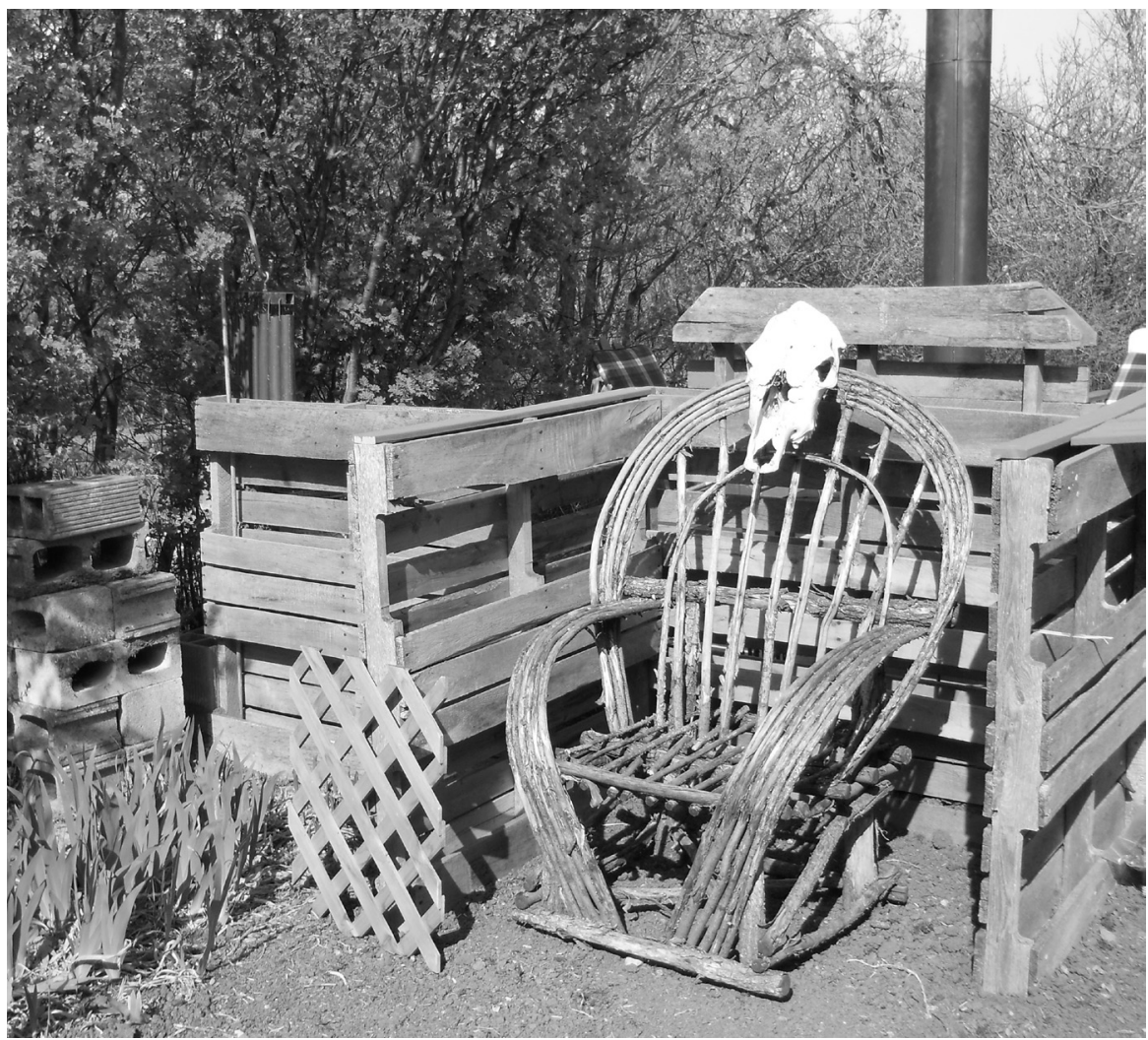


This summer, the sitting area on our patio was due for an update. We had a skull so we put it up on a decorative chair. Soon, the wren was busy flitting about. We looked into the brain cavity and saw the nest. It didn't matter that we used the patio almost daily, the birds stayed and raised a family. This is a picture of the young wrens in the skull nest.
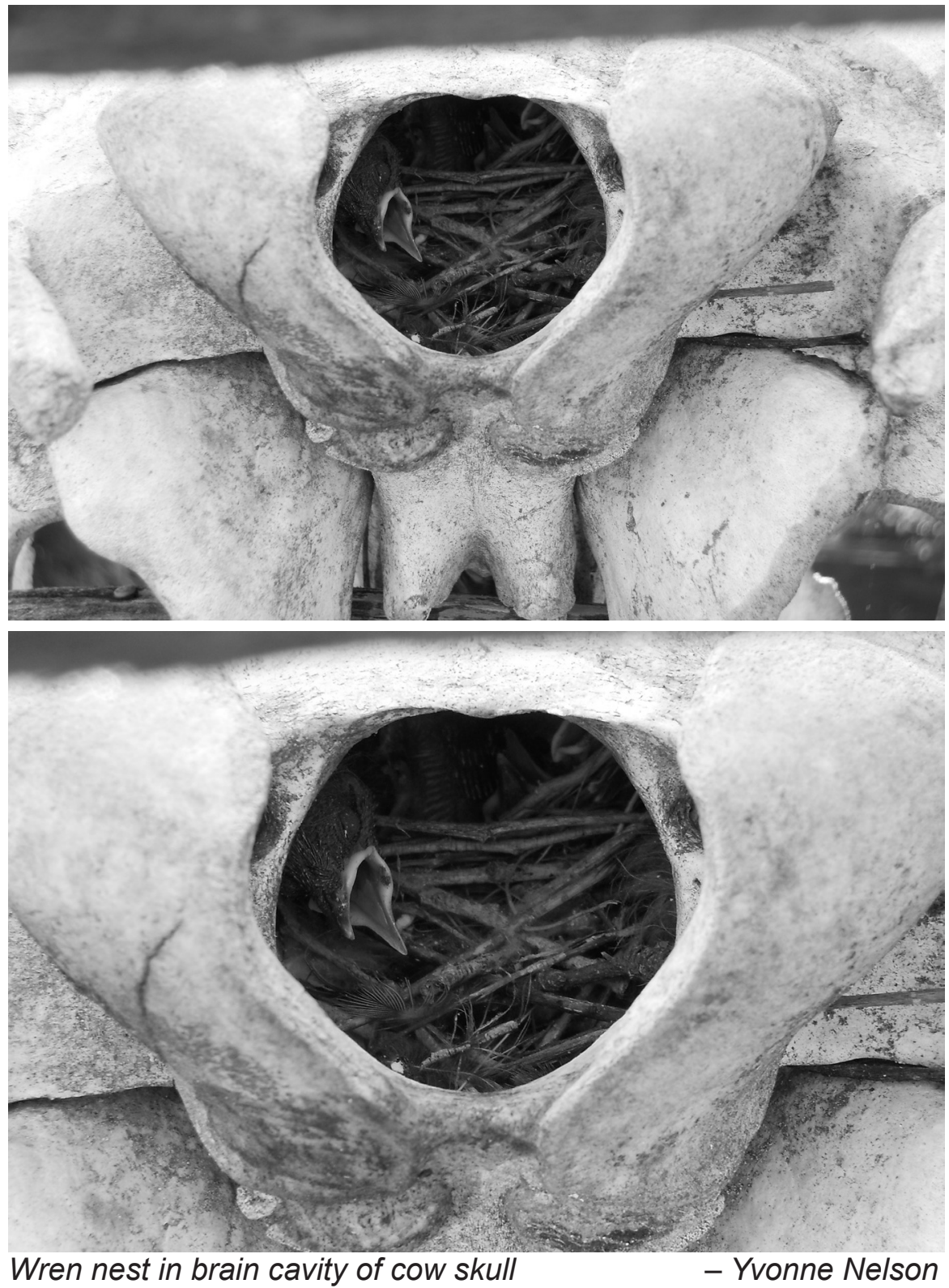